\title{
Vaginal Vibrator in the Rectum of a Young Man
}

\author{
Sergio Merino-Salas • Miguel Angel Arrabal-Polo • \\ Miguel Arrabal-Martin
}

Published online: 19 December 2008

(C) Springer Science+Business Media, LLC 2008

A healthy, 28-year-old man presented to the Emergency Services at our hospital because $5 \mathrm{~h}$ ago, while he practiced sex with his girlfriend, she introduced a sexual toy (vibrator) across the anal orifice (Fig. 1). Due to suction, the object stayed in the rectum (Haft, Benjamin, \& Wagner, 1976). The patient tried to extract the vibrator without success over a $4 \mathrm{~h}$ period. We attempted to touch the object with rectal tact, but it was impossible to extract it. We tried to extract it with

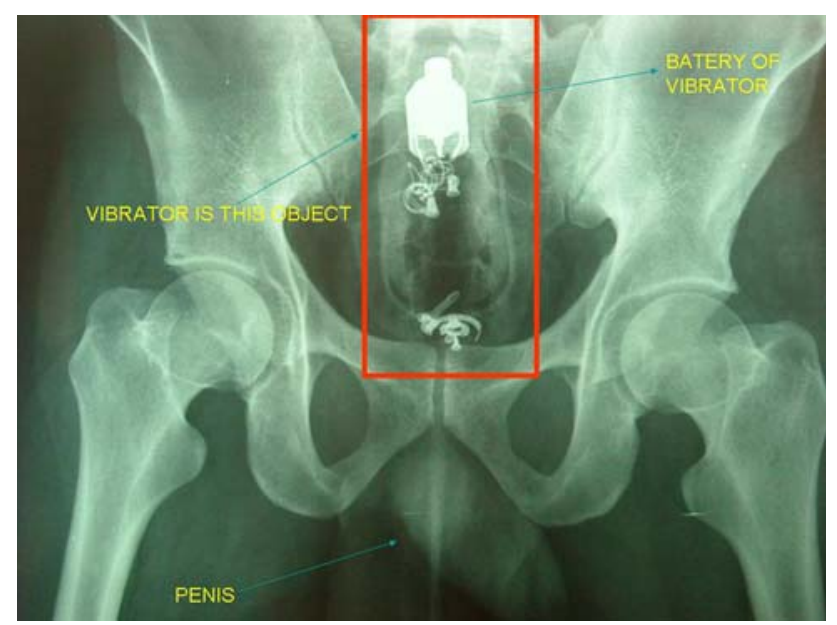

Fig. 1 Radiograph of the vibrator in the rectum

S. Merino-Salas - M. A. Arrabal-Polo - M. Arrabal-Martin Department of Urology, San Cecilio University Hospital, Avenida Doctor Oloriz, 18, 18012 Granada, Spain

M. A. Arrabal-Polo ( $\square)$

143 Camino de Ronda Street, $4^{\circ}$ F, 18003 Granada, Spain

e-mail: arrabalp@ono.com flexible endoscopy, but it was not possible, so we extracted the object by anoscopy and extraction with tweezers. The vibrator measured $18 \mathrm{~cm}$ in length and $3 \mathrm{~cm}$ in diameter. The main risk of this practice is vibrator-produced rectal perforation with peritonitis and fatal resolution (Waraich, Hudson, \& Iftikhar, 2007).

\section{References}

Haft, J. S., Benjamin, H. B., \& Wagner, M. (1976). Vaginal vibrator lodged in rectum. British Medical Journal, 1, 626.

Waraich, N. G., Hudson, J. S., \& Iftikhar, S. Y. (2007). Vibrator-induced fatal rectal perforation. New Zealand Medical Journal, 120, U2685. 